\title{
One hundred pregnancies after treatment with pulsatile luteinising hormone releasing hormone to induce ovulation
}

\author{
R Homburg, A Eshel, N A Armar, M Tucker, P W Mason, J Adams, J Kilborn, I A Sutherland, \\ H S Jacobs
}

\begin{abstract}
Objective-To review treatment with pulsatile luteinising hormone releasing hormone in infertile women who do not ovulate and are resistant to clomiphene after 100 pregnancies achieved with this
\end{abstract} treatment.

Design-Retrospective analysis of 146 courses of treatment over 434 cycles.

Setting-Infertility clinic.

Patients-118 Women whose failure to ovulate was due to idiopathic hypogonadotrophic hypogonadism $(n=39)$, amenorrhoea related to low weight $(n=17)$, organic pituitary disease $(n=15)$, or polycystic ovaries $(n=47)$.

Interventions - Dose of $15 \mu \mathrm{g}$ luteinising hormone releasing hormone/pulse subcutaneously every 90 minutes given with a miniaturised pump throughout cycle monitored by ultrasound. Women with hypogonadotrophic hypogonadism had 48 courses, women with amenorrhoea related to low weight 23 , women with organic pituitary disease 18 , and women with polycystic ovaries 57 .

End point-Follow up of 100 pregnancies achieved in 77 women during six years after introducing treatment.

Measurements and main results-One hundred pregnancies (seven multiple, 28 miscarriages). Cumulative rates of pregnancy were $93-100 \%$ at six months in women with idiopathic hypogonadotrophic hypogonadism, amenorrhoea related to low weight, and organic pituitary disease. In women with polycystic ovaries (cumulative rate of pregnancy $74 \%$ ) adverse prognostic factors were obesity, hyperandrogenism, and high luteinising hormone concentrations, which were also associated with a high rate of early pregnancy loss.

Conclusions - Treatment with pulsatile luteinising hormone releasing hormone is safe, simple, and effective, and the preferred method of inducing ovulation in appropriately selected patients. Compared with exogenous gonadotrophin treatment there is little need for monitoring, no danger of hyperstimulation, and a low rate of multiple pregnancies.

\section{Introduction}

Restoring ovulation in women in whom failure to ovulate is the sole cause of infertility yields a fertility rate similar to that in normal women.' The ideal ovulatory treatment for in vivo fertilisation should produce unifollicular ovulation as efficiently as possible while avoiding hyperstimulation, multiple pregnancies, and undue inconvenience to the patient. The choice of treatment depends on the underlying cause of the failure to ovulate. ${ }^{2}$

Since the first reports that treatment with pulsatile luteinising hormone releasing hormone could result in ovulation and pregnancy in women with hypogonadotrophic hypogonadism in whom antioestrogen treatment had failed ${ }^{3}$ we have used it as an alternative to gonadotrophin treatment in various groups of patients. ${ }^{4-6}$ After achieving the 100th pregnancy we reviewed our experience with this treatment from a clinical viewpoint. This report concentrates on selection of patients, efficiency of treatment, prognostic factors, and the outcome of pregnancy.

\section{Patients and methods}

The 118 patients selected for treatment had not been ovulating, were resistant to clomiphene, and had been fully investigated for other causes of infertility. ${ }^{2}$ They were classified according to the underlying cause of failure of ovulation. Of those with hypogonadotrophic hypogonadism, 34 had isolated idiopathic hypogonadotrophic hypogonadism and five had Kallman's syndrome (48 courses of treatment); 17 had amenorrhoea related to loss of weight, partially regained before treatment was started, associated with multicystic ovaries ( 23 courses); and 15 had organic pituitary disease (18 courses). A separate group of 47 patients with ultrasonically diagnosed polycystic ovaries ${ }^{7}$ had 57 courses of treatment.

Treatment with pulsatile luteinising hormone releasing hormone (Fertiral, Hoechst UK) was started by the subcutaneous route with the needle placed in the upper forearm. The intravenous route was used in 14 patients who did not respond to subcutaneous administration. One of these patients developed septicaemia and, though the condition resolved rapidly, we subsequently used an alternative approach in those not responding to subcutaneous treatment, adding oral clomiphene citrate, $100 \mathrm{mg} /$ day for five days, to treatment with subcutaneous pulsatile luteinising hormone releasing hormone. A dose of $15 \mu \mathrm{g}$ luteinising hormone releasing hormone per pulse was used, and one pulse was delivered every 90 minutes, which gave a total dose of $240 \mu \mathrm{ig}$ daily. Almost all the patients used the direct drive miniaturised pump designed by Sutherland et al,${ }^{8}$ but a few used a Graseby portable pulsatile syringe driver. A detailed description of the practical methods used to give the hormone has been reported elsewhere. ${ }^{9}$

Treatment was monitored by observing follicular growth, endometrial thickness, and uterine size with ultrasound imaging. ${ }^{10}$ The development of follicles, the probable time of ovulation, and confirmation of ovulation were charted. Treatment was continued until a gestation sac was detected by ultrasonography. If no follicular development was seen after 28 days' treatment the patient was deemed as having failed to respond. Eighteen patients who had not responded to the hormone previously and after a minimum of 12 days of subcutaneous treatment in a new cycle were given clomiphene citrate $(100 \mathrm{mg} /$ day for five days) concurrently with the hormone." Human chorionic gonadotrophin was given (in a single dose of 10000 IU) when follicular growth had been detected on ultrasonography during a preceding cycle but ovulation had not occurred. It was also given in a few
Correspondence to:

Professor Jacobs. 
cases in which a large dominant follicle had persisted for more than five days.

Statistical analyses were performed with MannWhitney and $\chi^{2}$ tests.

\section{Results}

The 118 patients received 146 courses of treatment over 434 cycles, of which 304 were ovulatory (table I). The 100 pregnancies were achieved in 77 patients and resulted in 58 singleton deliveries, six twin deliveries, and one triplet delivery. At the time of writing six patients were pregnant beyond 12 weeks' gestation. There were 28 miscarriages, 19 of which occurred within four weeks after conception (early pregnancy loss), and one tubal pregnancy (table II).

Table III shows the cumulative rates of pregnancy over six months calculated by life table analysis ${ }^{12}$ for the various treatment groups. Of the 36 courses of treatment that were stopped within six months, 18 were in patients who had not responded in one to four cycles and stopped treatment at their own request or were offered alternative treatment. The other 18 were in patients who ovulated in one to four cycles: 14 stopped treatment for personal reasons, two were referred for gamete intrafallopian transfer, and two left the country. Patients with isolated idiopathic hypogonadotrophic hypgonadism (cumulative rate of pregnancy $93 \%$ after six months' treatment), patients who did not ovulate despite adequate weight gain after having amenorrhoea related to low weight (cumulative rate of pregnancy $95 \%$ after six months), and patients who had residual pituitary tissue after an operation on the pituitary benefited most from this treatment.

Patients with organic pituitary disease who had received pituitary irradiation or radical surgery responded poorly, and treatment was stopped in three such cases after one, two, and four cycles respectively. The remaining patients in this group ovulated and conceived by six months. Patients with ultrasonically diagnosed polycystic ovaries had a cumulative rate of pregnancy of $74 \%$ after six months' treatment. When ovulation was achieved regularly rates of pregnancy returned to those expected in the normal population.' Both obesity and hyperandrogenism

TABI.E I-Results of treatment with pulsatile luteinising hormone releasing hormone according to underlying cause of failure to ovulate

\begin{tabular}{lcccc}
\hline & $\begin{array}{c}\text { Hypogonadotrophic } \\
\text { hypogonadism }\end{array}$ & $\begin{array}{c}\text { Amenorhoea related } \\
\text { to low weight }\end{array}$ & $\begin{array}{c}\text { Organic } \\
\text { pituitary disease }\end{array}$ & $\begin{array}{c}\text { Polycystic } \\
\text { ovaries }\end{array}$ \\
Total
\end{tabular}

TABLE II - Outcome of 100 pregnancies achieved with luteinising hormone releasing hormone treatment according to underlying cause of failure to ovulate

\begin{tabular}{|c|c|c|c|c|c|}
\hline & $\begin{array}{l}\text { Hypogonadotrophic } \\
\text { hypogonadism }\end{array}$ & $\begin{array}{c}\text { Amenorrhoca related } \\
\text { to low weight }\end{array}$ & $\begin{array}{c}\text { Organic } \\
\text { pituitary disease }\end{array}$ & $\begin{array}{c}\text { Polycystic } \\
\text { ovaries }\end{array}$ & Total \\
\hline Pregnancies & 38 & 21 & 11 & 30 & 100 \\
\hline Multiple pregnancies & 4 & & & 3 & 7 \\
\hline Delivered and continuing pregnancies & 31 & 16 & 6 & 18 & 71 \\
\hline Early pregnancy loss $<+$ weeks after ovulation & 2 & 5 & 2 & 10 & 19 \\
\hline Miscarriage $>4$ weeks after orulation & 4 & & 3 & 2 & 9 \\
\hline Tubal pregnancy & 1 & & & & 1 \\
\hline
\end{tabular}

TABLE III -Cumulative rate of pregnancy by life table analysis, during treatment with luteinising hormone releasing hormone according to underlving causes of failure to ovulate

\begin{tabular}{|c|c|c|c|c|}
\hline Months of treatment & $\begin{array}{c}\text { No } \\
\text { not pregnant } \\
\text { at start of month }\end{array}$ & $\begin{array}{l}\text { No who } \\
\text { became pregnant } \\
\text { during interval }\end{array}$ & $\begin{array}{l}\text { Nowho } \\
\text { dropped } \\
\text { out }\end{array}$ & $\begin{array}{c}\text { Cumulative } \\
\text { rate of pregnancy } \\
(\%)\end{array}$ \\
\hline
\end{tabular}

Hypogonadotrophic hypogonadism

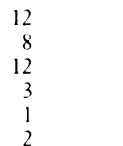

25
42
73
82
86
93

Amenorrhoea related to weight

18

23
18
8
6
3
1

5
9

2

Organic pituitary disease

18
14
7
6
3
3

57
49
31
21
14
11

3
3
1

3

Polycystic oriaries

$\begin{array}{ll}57 & 7 \\ 49 & 8 \\ 31 & 4 \\ 21 & 4 \\ 14 & 3 \\ 11 & 4\end{array}$

associated with polycystic ovaries were associated with a poor outcome. The mean (range) body mass index (weight $(\mathrm{kg}) /\left(\right.$ height $\left.(\mathrm{m})^{2}\right)$; normal 20-25) was $25 \cdot 7$ $(20.6-34.8) \mathrm{kg} / \mathrm{m}^{2}$ in the 13 patients who never ovulated during this treatment compared with 22.6 $(18 \cdot 6-33 \cdot 8) \mathrm{kg} / \mathrm{m}^{2}$ in the 44 who ovulated in at least one cycle $(U=74.5, p=0 \cdot 02)$. Few patients with polycystic ovaries with a body mass index of more than $25 \mathrm{~kg} / \mathrm{m}^{2}$ responded to treatment. Mean (range) serum testosterone concentrations were $2 \cdot 9(1 \cdot 5-5 \cdot 1) \mathrm{nmol} / 1$ in the 13 who never ovulated compared with $2 \cdot 0$ $(0 \cdot 5-4 \cdot 0) \mathrm{nmol} / \mathrm{l}$ in the 44 who ovulated in at least one cycle $(U=101, p=0.01)$. Neither serum follicle stimulating hormone nor serum prolactin concentrations influenced ovulation or rates of pregnancy.

Serum luteinising hormone concentrations were measured basally in all patients with polycystic ovaries and throughout the follicular phase of each cycle during treatment in the last 23 of them. The basal concentrations and those determined at the time of maximum follicular growth (five days before ovulation with a dominant follicle $10-15 \mathrm{~mm}$ in diameter) were related to ovulation and conception. Basal luteinising hormone concentrations were significantly lower in the 30 women who conceived (mean $12 \cdot 4$ (range $1 \cdot 3-29 \cdot 0) \mathrm{IU} / \mathrm{l})$ than in the 27 who did not $(19 \cdot 0$ $(2 \cdot 3-50 \cdot 0) \quad \mathrm{IU} / \mathrm{l} ; \mathrm{U}=236, \quad \mathrm{p}=0 \cdot 02)$. Luteinising hormone concentrations at the time of maximum follicular growth were significantly lower in the 19 who ovulated $(9 \cdot 4(2 \cdot 9-35 \cdot 4)$ IU/1) than in the four who did 
not $(29 \cdot 0(7 \cdot 0-50 \cdot 0) \mathrm{IU} / \mathrm{l} ; \mathrm{U}=12, \mathrm{p}=0 \cdot 03)$ and in the 10 who conceived $(6 \cdot 2(2 \cdot 9-8 \cdot 5) \mathrm{IU} / \mathrm{l})$ than in the 13 who $\operatorname{did} \operatorname{not}(17 \cdot 9(4 \cdot 0-50 \cdot 0) \mathrm{IU} / \mathrm{l} ; \mathrm{U}=27, \mathrm{p}=0 \cdot 02)$.

Table II shows the obstetric outcome of the 100 pregnancies. Seventy one pregnancies were delivered or continued beyond 12 weeks' gestation. Of the 28 miscarriages, 12 occurred in the 30 pregnancies in patients with polycystic ovaries compared with 16 in the 70 pregnancies in patients with other diagnoses $\left(\gamma^{2}=1 \cdot 1, p=0 \cdot 3\right)$. An influence of polycystic ovaries on the rate of miscarriage was, however, observed when early pregnancy loss was considered. Ten of the 30 pregnancies in patients with polycystic ovaries terminated within four weeks after ovulation compared with nine of the 70 pregnancies in patients with other diagnoses $\left(\chi^{2}=4 \cdot 47, p=0 \cdot 03\right)$. Basal serum luteinising hormone concentrations in the 10 patients with the polycystic ovary syndrome who suffered an early pregnancy loss $(17.9(7 \cdot 0-29 \cdot 0)$ IU/l) were significantly higher than those in the 18 whose pregnancy progressed $(9.6(1 \cdot 3-29 \cdot 0) \quad \mathrm{IU} / \mathrm{l} ; \mathrm{U}=9$, $p=0 \cdot 01$ ), suggesting a possible hormonal cause of early pregnancy loss in these patients. ${ }^{13}$

One set of triplets and five sets of twins were delivered, and one of the continuing pregnancies was a twin pregnancy. All four multiple pregnancies in the patients with hypogonadotrophic hypogonadism were conceived in the first cycle, whereas the three multiple pregnancies in the patients with polycystic ovaries were conceived in the second, third, and sixth cycles. One patient with organic pituitary disease (after excision of a craniopharyngioma) was seen to have two gestational sacs on ultrasound scanning before having an early pregnancy loss 25 days after ovulation. One patient with partially recovered weight related amenorrhoea had two definable gestational sacs on ultrasound scanning at six weeks, one of which had disappeared by nine weeks. She went on to have an uneventful singleton pregnancy and delivery. Four of the seven patients who eventually delivered multiple infants had received human chorionic gonadotrophin, one intravenous luteinising hormone releasing hormone, and one a reduced dose of luteinising hormone releasing hormone $(7.5 \mu \mathrm{g} /$ pulse $)$ because multiple follicles had developed during treatment with the standard dose in previous cycles. Two of the patients with twins had strong family histories of multiple pregnancy.

Seven of the 14 patients given intravenous luteinising hormone releasing hormone ovulated and conceived after failing to respond to subcutaneous treatment. Of the patients given oral clomiphene citrate with subcutaneous pulsatile luteinising hormone releasing hormone, 12 of 14 patients with polycystic ovaries, one patient with amenorrhoea related to low weight, and one of three patients with organic pituitary disease ovulated.

No congenital abnormalities were detected at birth. All except three singleton pregnancies that progressed to 12 weeks proceeded to term (in one patient labour was induced at 33 weeks because of severe pre-eclamptic toxaemia, and two patients with polycystic ovaries had missed abortions at 18 and 22 weeks' gestation). The patient with a triplet pregnancy was successfully delivered by caesarean section at 32 weeks because of hypertension and proteinuria.

\section{Discussion}

This clinical analysis of our experience of using pulsastile luteinising hormone releasing hormone to treat infertile women who do not ovulate has shown it to be safe, simple, and effective and the preferred method of inducing ovulation in appropriately selected patients who are resistant to clomiphene. In patients in whom failure to ovulate is the sole cause of infertility restoring regular ovulation by giving pulsatile luteinising hormone releasing hormone achieves cumulative rates of conception equal to those in the normal population.' This treatment was particularly efficient in restoring ovulation in patients with idiopathic hypogonadotrophic hypogonadism and partially recovered weight related amenorrhoea. In these two groups 167 of the 189 cycles were ovulatory. All the patients in the present series were resistant to clomiphene, and the alternative treatment to pulsatile luteinising hormone releasing hormone would usually be exogenous gonadotrophins. Comparison of the results of these two methods of treatment shows the advantages of pulsatile luteinising hormone releasing hormone, which has a lower rate of multiple pregnancy, has not resulted in hyperstimulation or any recorded birth defects, and has a similar rate of miscarriage. The rate of miscarriage in the present series included a large proportion of pregnancy losses in the few weeks after ovulation, which we suspect were not always detected in earlier studies of treatment with gonadotrophin.

Most patients were highly motivated and soon adapted to the addition of the pump to their daily routine with minimum inconvenience. The pulse rate of the generator did not need to be altered as it produced all the morphological and hormonal features of an apparently normal ovulatory cycle, ${ }^{14}$ even though physiologically the frequency of pulses is reduced at night ${ }^{15}$ and the pattern of the pulses is phase specific. ${ }^{16}$ As the treatment was continued throughout the luteal phase no support with injections of human chorionic gonadotrophin was necessary. If treatment with luteinising hormone releasing hormone is stopped at ovulation with no luteal phase support a short luteal phase and menstruation will ensue. ${ }^{7}$ When luteinising hormone releasing hormone is stopped in the mid-luteal phase for 24 hours the luteal phase may be "rescued" by reinstating the luteinising hormone releasing hormone treatment. ${ }^{18}$ When pump treatment has been stopped at ovulation and human chorionic gonadotrophin given throughout the luteal phase results have not been as good; the regimen is less physiological and more prone to non-compliance."

The subcutaneous route has proved itself adequately, and the potential advantage of the reduced dose (and costs) with the intravenous route is offset by the dangers of infection and inconvenience to the patient. Like others ${ }^{19}$ we found that inserting the needle in the upper forearm provided more complete absorption than occurs from an abdominal site. Before we started using intravenous luteinising hormone releasing hormone or gonadotrophin treatment in patients who do not ovulate with subcutaneous treatment we found that its combination with oral clomiphene was worth trying and often produced a good response." This response was not accompanied by a detectable change in gonadotrophin concentrations, which suggests that clomiphene acts directly on the ovary in these cases."

One of the main advantages of treatment with pulsatile luteinising hormone releasing hormone compared with other forms of inducing ovulation is the low rate of multiple pregnancies. Of the seven patients with multiple pregnancies in the present series, two had strong family histories of multiple pregnancies, one of whom had previously delivered a singleton infant after treatment with luteinising hormone releasing hormone. The use of human chorionic gonadotrophin at mid-cycle may also be implicated as four of the seven patients received this treatment compared with seven out of the 111 other patients treated. The fact that all four multiple pregnancies in the group with hypogonadotrophic hypogonadism 
were conceived in the first cycle during treatment is consistent with the report of Braat et al, who collated national figures for treatment with luteinising hormone releasing hormone in The Netherlands and found a significant association of multiple pregnancies with the first cycle. ${ }^{20}$ In hypogonadotrophic hypogonadism the high occurrence of multiple pregnancy in the first cycle compared with subsequent cycles suggests that the lack of a preceding luteal phase may result in either an exaggerated pituitary response to luteinising hormone releasing hormone or an exaggerated ovarian response to normal gonadotrophin stimulation. It is analogous to the development of multiple follicles and lack of a dominant follicle that characterise menarche. ${ }^{2}$ The already low rate of multiple pregnancies with luteinising hormone releasing hormone treatment could probably be reduced even further by avoiding giving human chorionic gonadotrophin at mid-cycle, by withdrawing treatment when multiple follicles are detected with ultrasound, and by using lower doses of luteinising hormone releasing hormone in the first cycle of treatment in patients with hypogonadotrophic hypogonadism.

We relied on ultrasound monitoring to chart the development of the dominant follicle and effect of the treatment and intentionally collected more data than were essential for purely clinical purposes. Particularly in cases of hypogonadotrophic hypogonadism, only limited surveillance is necessary to guide the patient in timing intercourse, evaluating the postcoital test results, and confirming ovulation because the treatment is so predictable. Human chorionic gonadotrophin in mid-cycle is rarely required, and there is no danger of hyperstimulation so monitoring may be kept to a minimum.

Theoretically, patients who have deficient secretion of luteinising hormone releasing hormone and intact pituitaries should be optimally suited to treatment with pulsatile luteinising hormone releasing hormone as substitution treatment, and this is borne out by our results. Those with idiopathic hypothalamic hypogonadism (some with Kallman's syndrome) and those with partially recovered weight related amenorrhoea associated with multicystic ovaries responded with an extremely high rate of ovulation and conception. The excellent outcome of treatment in these patients must not, however, tempt doctors to induce ovulation in patients with unresolved amenorrhoea related to low weight as the obstetric outcome in such patients is prejudiced. ${ }^{22}$ The rate of spontaneous miscarriage in the group was no greater than that in the general population.

The response to treatment with luteinising hormone releasing hormone in patients with organic pituitary disease, excluding those who had undergone irradiation, was surprisingly good; this treatment can thus be recommended for patients who have residual pituitary tissue after an operation on the pituitary.

Treatment of infertility in women with polycystic ovaries who do not ovulate and are resistant to clomiphene should be reserved for those who are not overly obese and have serum luteinising hormone concentrations less than $12 \mathrm{IU} / \mathrm{l}$.

We thank Dr P Magill of Hoechst UK for generous supplies of luteinising hormone releasing hormone and the gift of an ultrasound scanner; Middlesex Hospital Special Trustees' Fund for buying some of the pumps; and Mr G R Chambers and $\mathrm{Mr}$ D Presswell of the National Institute for Medical Research, London, for their support with the pump technology.

1 Hull MGR, Savage PE, Jacobs HS. Investigation and treatment of amer.

2 Jacobs HS, Hull MGR, Murray MAF, Franks S. Therapy orientated diagnosis of secondary amenorrhoea. Horm Res 1975;6:268-87.
3 Leyendecker G, Wildt L, Hansmann M. Pregnancies following chronic intermittent (pulsatile) administration of $\mathrm{GnRH}$ by means of a portable pump ("Zyklomat") - a new approach to the treatment of infertility in hypothalamic amenorrhoea. I Clin Endocrinol Metab 1980;51:1214-6.

4 Mason P, Adams J, Morris DV, et al. Induction of ovulation with pulsatile luteinising hormone releasing hormone. Br Med f 1984;288:181-5.

5 Eshel A, Abdulwahid NA, Armar NA, Adams J, Jacobs HS. Pulsatile luteinising hormone-releasing hormone therapy in women with polycistic luteinising hormone-releasing hormone thera
ovary syndrome. Fertil Steril 1988;49:956-60.

6 Morris DV, Abdulwahid NA, Armar NA, Jacobs HS. Induction of fertility in patients with organic hypothalamic-pituitary disease: response to treatment with LHRH. Feril Steril 1987:47:54-9.

7 Adams J, Franks S, Polson DW, et al. Multifollicular ovaries: clinical and endocrine features and response to pulsatile gonadotrophin releasing hormone. Lancet 1985 ;ii: $1375-8$

8 Sutherland IA, White S, Chambers GR, et al. A miniature infuser for the pulsatile administration of LHRH. F Biochem Eng 1984;6:129-33.

9 Armar NA, Tan SL, Eshel A, Jacobs HS, Adams J, Sutherland IA. Practical aspects of pulsatile LHRH therapy. Br f Hosp.Med 1987:37:429-36.

10 Adams JM, Tan SL, Wheeler M, Morris DV, Jacobs HS, Franks S. Uterine growth in the follicular phase of spontaneous ovulatory crcles and durin luteinising hormone releasing hormone induced cycles in women with normal or polycystic ovaries. Fertil Steril 1988;49:52-5.

11 Homburg R, Eshel A, Armar NA, Tucker M, Adams J, Jacobs HS. Synergism of pulsatile LHRH therapy with oral clomiphene treatment. Gunecol Eindocrinol 1988:2:59-66.

12 Cooke ID, Sulaiman RA, Lenton EA, Parsons RJ. Fertility and infertility statistics: their importance and application. Clin Obstet Gymuecol 1981;8 $531-48$.

13 Homburg R, Armar NA, Eshel A, Adams J, Jacobs HS. The influence of serum luteinising hormone concentrations on ovulation, conception, and early pregnancy loss in patients with polycystic ovary syndrome. Br.Med 1988;297:1024-6.

14 Jacobs HS. Induction of ovulation in women using pulsatile LHRH - clinical results. In: Bloom SR, Jacobs HS, eds. Therapeutic applications of $L H R H$ London: Royal Society of Medicine Services, 1986:99-109.

15 Crowley WF, Filicori M, Spratt DI, Santoro NF. The physiology of gonadotropin-releasing hormone ( $\mathrm{inRH}$ secretion in men and women. Recent Prog Horm Res 1985;41:473-8.

16 Yen SSC, Tsai CC, Naftolin F, Vandenburg G, Ajabor L. Pulsatile patterns of gonadotropin release in subjects with and without ovarian function. $7 \mathrm{Clin}$ Endocrinol Metab 1972:34:671-5.

17 Franks S, van der Spuv ZM, Mason WP, Adams J, Jacobs HS. Luteal function after ovulation induction by pulsatile luteinising hormone releasing hormone. In: Jeffcoate SL, ed. The luteal phase. Chichester: John Wiley, 1985:89-100

18 Polson DW, Sagle M, Mason HD, Kiddy D, Franks S. Recovery of luteal function after interruption of gonadotrophin secretion in the mid-luteal phase of the menstrual cycle. Clin Endocrinol 1987;26:597-600.

19 Blunt SM, Menon BKV, Butt WR. Pulsatile LHRH in hypogonadotrophic hypogonadism. In: Bloom SR, Jacobs HS, eds. Therapeutic applications of LHRH. London: Royal Society of Medicine Services, 1986:89-98.

20 Braat DDM. Boghelman D, Coelingh-Bennink HJT, et al. The outcome of pregnancies established in GnRH induced cycles with specia! reference to the multiple pregnancies in five Dutch centres. In: Coelingh-Bennink HJT, Dogterom AA, Lappohn RE, Rolland R, Shoemaker J, eds. Pulsatile GinRH. Haarlem: Ferring, 1985.

21 Stanhope R, Brook CGD, Pringle PJ, Adams J, Jacobs HS. Induction of puberty by pulsatile gonadotrophin releasing hormone. Lancet 1987;ii $552-5$

22 van der Spuy ZM, Steer PJ, McCusker M, Steele SJ, Jacobs HS. Pregnancy outcome in underweight women following spontaneous and induced ovulation. Br Med f 1988;296:962-5

(Accepted 21 December 1988

\section{ANY QUESTIONS}

\section{Is nicotine chewing gum carcinogenic?}

Nicotine chewing gum consists of nicotine in a food grade chewing gum base. Nicotine itself is not carcinogenic, and the possibility of its significant metabolic conversion to a carcinogenic nitrosamine after absorption is unlikely. The other constituents are all thought to be safe as foods, food additives, or pharmaceutical excipients and may, therefore, be accepted as free from carcinogenic risk. By contrast, chewing tobacco contains known carcinogensfor example, polycyclic aromatic hydrocarbons and nitrosamines-which are not present in nicotine chewing gum.

The unique taste of nicotine chewing gum is caused by the nicotine and is not indicative of the kind of irritation that leads to cell proliferation or an increased risk of developing cancer. Idiosyncratic sensitivity to the gum content of the product is rare. When it occurs subjects should obviously not use the product, but their symptoms are unrelated to the risk of cancer. - FRANCIS J ROE, consultant in toxicology, London 